\title{
Differences in Curing Behavior of Cocured and IPN Materials
}

\author{
MU-SHIH LIN, CHUN-CHEN CHIU \\ Department of Applied Chemistry, National Chiao-Tung University, Hsinchu, Taiwan 30050
}

Received 27 December 1999; accepted 13 June 2000

\begin{abstract}
This study addressed the blending and cocuring of resole and epoxy, using $\mathrm{NaOH}$ and 4,4'-diaminodiphenylmethane as curing agents. IR band shifts regarding the molecular interactions were investigated with FTIR. Exothermic peak shifts during cocuring reactions were studied with dynamic DSC. Viscosity increases were measured with a Brookfield LVT viscometer at $100^{\circ} \mathrm{C}$. The dynamic mechanical properties of the cocured samples were investigated using rheometric dynamic spectroscopy (RDS). Experimental results revealed that the molecular interactions between resole and epoxy resulted in good compatibility as shown by the single damping peak in the RDS curve and the single glass transition for each cocured sample. Also apparent were accelerated curing rates, leading to shifts of the exothermic peaks to lower temperature and faster viscosity increases. Nevertheless, enhanced gel fractions and increased glass-transition temperatures $\left(T_{g}\right)$ of the samples were generally observed for this cocured system. The average molecular weight between crosslinked points calculated for the cocured materials also showed much less than the two components. These curing behaviors were quite different from those of the Interpenetrating Polymer Network (IPN) materials, which usually indicated lowered gel fractions, decreased $T_{g}$, and higher average molecular weight between crosslinkings than for components. () 2001 John Wiley \& Sons, Inc. J Appl Polym Sci 80: 963-969, 2001
\end{abstract}

\section{INTRODUCTION}

Our previous studies on the curing behaviors of fully interpenetrating polymer networks ${ }^{1}$ revealed that exothermic peaks shift to a higher and broader temperature range, and a retarded viscosity increase was generally found. These findings are reasonably consistent with lower gel fractions and lower glass-transition temperatures $\left(T_{g}\right)$ for fully IPNs, as compared with the respective components. Our kinetic study for fully IPN materials consistently showed lower rate constants and higher activation energies during IPN formation. ${ }^{2}$ Based on these findings, we proposed

Correspondence to: M.-S. Lin.

Contract grant sponsor: National Science Council of Taiwan; contract grant number: NSC 88-2216-E-009-023.

Journal of Applied Polymer Science, Vol. 80, 963-969 (2001)

(c) 2001 John Wiley \& Sons, Inc. an effect of network interlock to interpret the curing behaviors of IPNs ${ }^{1,2}$ : IPN materials where chains entangle physically between the two networks would result in an increased steric hindrance and a decreased chain mobility, thus explaining the increased activation energies and retarded rate constants during IPN formation.

In our present study, concerning the cocuring of two thermosets, resole and epoxy, chemical crosslinking between the two networks resulted in only one whole network containing two components. An adverse curing behavior was found for this cocured material. This article reports on and discusses the different phenomena found.

\section{EXPERIMENTAL}

Resole was prepared by the method cited in the literature. ${ }^{3,4}$ Epoxy in the form of diglycidyl 


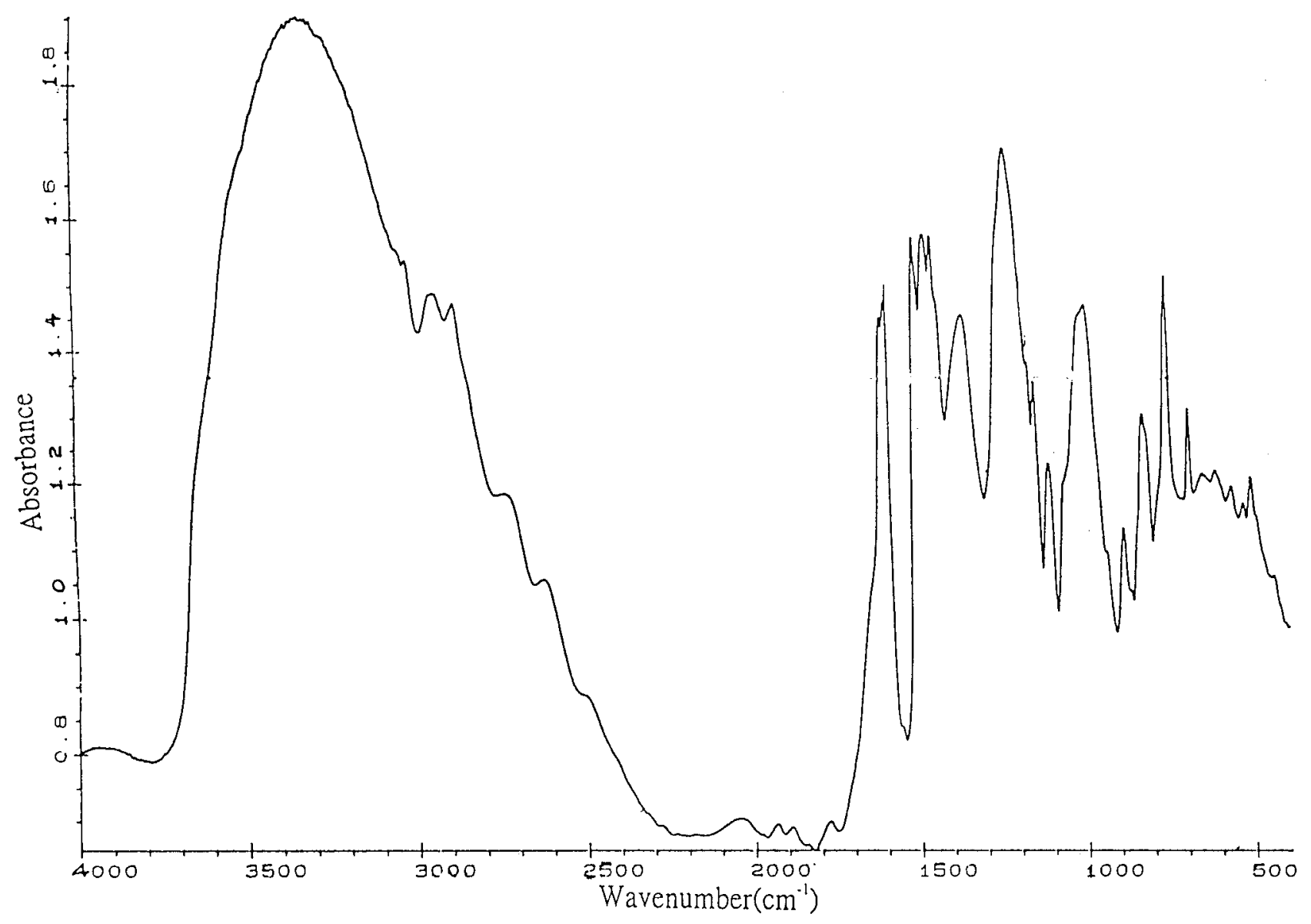

Figure 1 FTIR spectrum of resole.

ether of bisphenol-A (DGEBA, Epon 815) with an epoxy equivalent weight of 194 was obtained from Shell Company, Taiwan. Various weight ratios of epoxy:resole-100:0, 75:25, 50:50, 25: 75 , and 0:100-were blended. MDA (20\% on epoxy) and $\mathrm{NaOH}$ ( $1 \%$ on resole) were used as curing agents for each indicated component. Each blend was poured into Teflon molds, followed by precuring at $110^{\circ} \mathrm{C}$ for $5 \mathrm{~h}$, then an additional postcuring at $160^{\circ} \mathrm{C}$ for $2 \mathrm{~h}$.

A Nicolet 520 FTIR with a resolution of 0.5 $\mathrm{cm}^{-1}$ was employed to monitor the IR band shift. For curing dynamic differential scanning calorimetry (DSC), liquid blends containing curing agents were sealed in the pressured DSC cells. All DSC thermograms were obtained by running the samples in a nitrogen atmosphere at a heating rate of $10^{\circ} \mathrm{C} \mathrm{min}^{-1}$. Gel fractions were measured with a Soxhlet extractor, after $48 \mathrm{~h}$ of continuous extraction, using acetone as a solvent. Viscosity changes during cocuring reactions were measured at $100^{\circ} \mathrm{C}$ with a Brookfield LVT viscometer. The dynamic mechanical properties were studied with a rheometric dynamic spectroscopy (RDS, Rheometic II) under a nitrogen atmosphere at a frequency of $1 \mathrm{~Hz}$ and a heating rate of $3^{\circ} \mathrm{C} \mathrm{min}^{-1}$, with a $0.2 \%$ strain at $31.4 \mathrm{rad} / \mathrm{s}$. The temperature ranged from -100 to $200^{\circ} \mathrm{C}$.

\section{RESULTS AND DISCUSSION}

Synthesis and characterization of resole followed the method cited in the literature. ${ }^{3,4}$ Its FTIR spectrum is shown in Figure 1. The broad absorption band from 3500 to $2500 \mathrm{~cm}^{-1}$ indicates a hydrogen-bonded resole. Absorption at 800 and $755 \mathrm{~cm}^{-1}$ confirms ortho and para $\mathrm{CH}_{2}$ linkage of phenol and at1230 $\mathrm{cm}^{-1}$ confirms the $\mathrm{C}-\mathrm{O}-\mathrm{C}$ linkage. The ${ }^{13} \mathrm{C}-\mathrm{NMR}$ spectrum of resole in $\mathrm{CD}_{3} \mathrm{OD}$ (solvent peaks from 48.1 to $49.5 \mathrm{ppm}$ ) is given in Figure 2. As revealed in the literature, ${ }^{4}$ peaks at $30.6,35.6$, and $41.1 \mathrm{ppm}$ confirm the $\mathrm{CH}_{2}$ linkages at, respectively, the $0-0,0-p$, and $p-p$ 


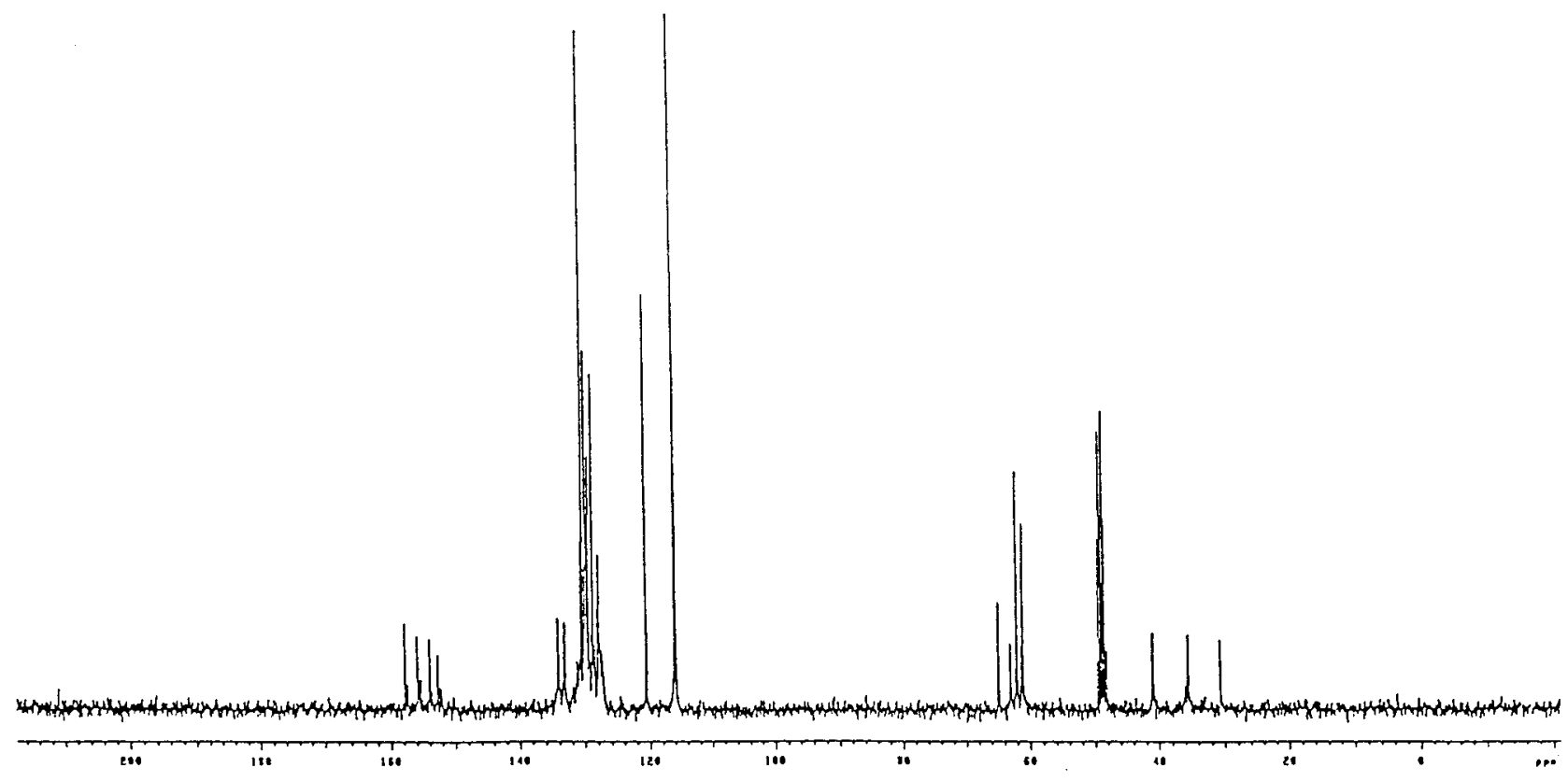

Figure $2{ }^{13} \mathrm{C}-\mathrm{NMR}$ spectrum of resole.

positions of phenol. The ortho carbon linked to the methylol group occurs at $65.0 \mathrm{ppm}$. Peaks at 115 $116,120.4-120.5,128.8$, and $157.6 \mathrm{ppm}$ represent the absorptions of carbons on the phenyl ring connected to the $\mathrm{OH}$ group and the ortho, meta, and para positions. For trisubstitute $\mathrm{CH}_{2}$-linked phenols, carbon linking to $\mathrm{OH}$ occurs between 152 and $157 \mathrm{ppm}$, while peaks for the other carbons overlap around 127-134 ppm. All these confirm the structure of resole.

The miscibility between epoxy (with a solubility parameter of 9.98) and resole (with a solubility parameter of 10.5) can be expected to occur using the method outlined by Small ${ }^{5}$ and Hoy. ${ }^{6}$ Figure 3 shows the shifts of $\mathrm{OH}$ absorption in resole. Pure resole has a broad $\mathrm{OH}$ stretching absorption around $3600-3100 \mathrm{~cm}^{-1}$, with a peak at 3300 $\mathrm{cm}^{-1}$ (Curve A). When epoxy was blended to resole, the absorption of $\mathrm{OH}$ shifted to a higher wavenumber. The more epoxy was incorporated, the higher were the frequency shifts of the $\mathrm{OH}$ absorption, since the miscibility at a molecular level between resole and epoxy (Curves B, C, and D) dilutes the extent of hydrogen bonding. Figure 4 shows the epoxy band shifts. Pure epoxy indicates an epoxy absorption at $917 \mathrm{~cm}^{-1}$ (Curve E). When resole was incorporated into epoxy, the epoxide absorption shifted to a lower wavenumber (Curves B, C, and D), presumably because of the hydrogen bonding formed between epoxide and the $\mathrm{OH}$ of resole. The compatibility of the cocured resole-epoxy is also shown by the single damping peak in RDS curves (Fig. 5) and the single $T_{g}$ in DSC thermograms (Fig. 6) for each composition. Figure 7 shows the dynamic DSC thermograms of

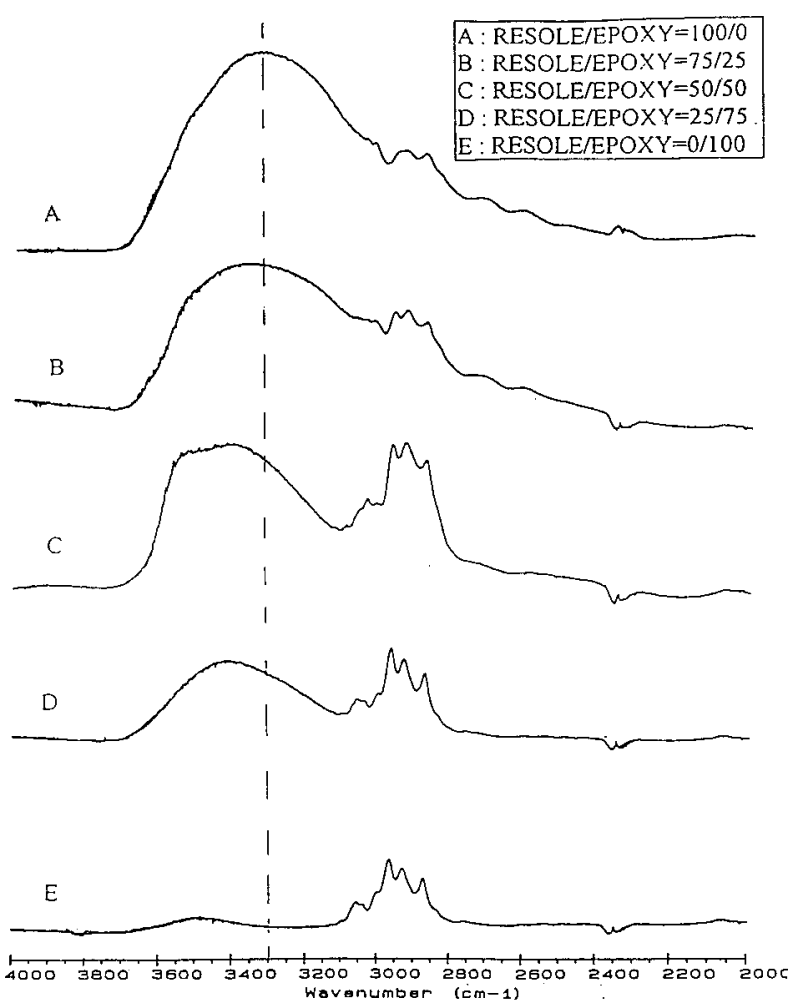

Figure $3 v_{\mathrm{OH}}$ band shifts in resole-epoxy blends. 


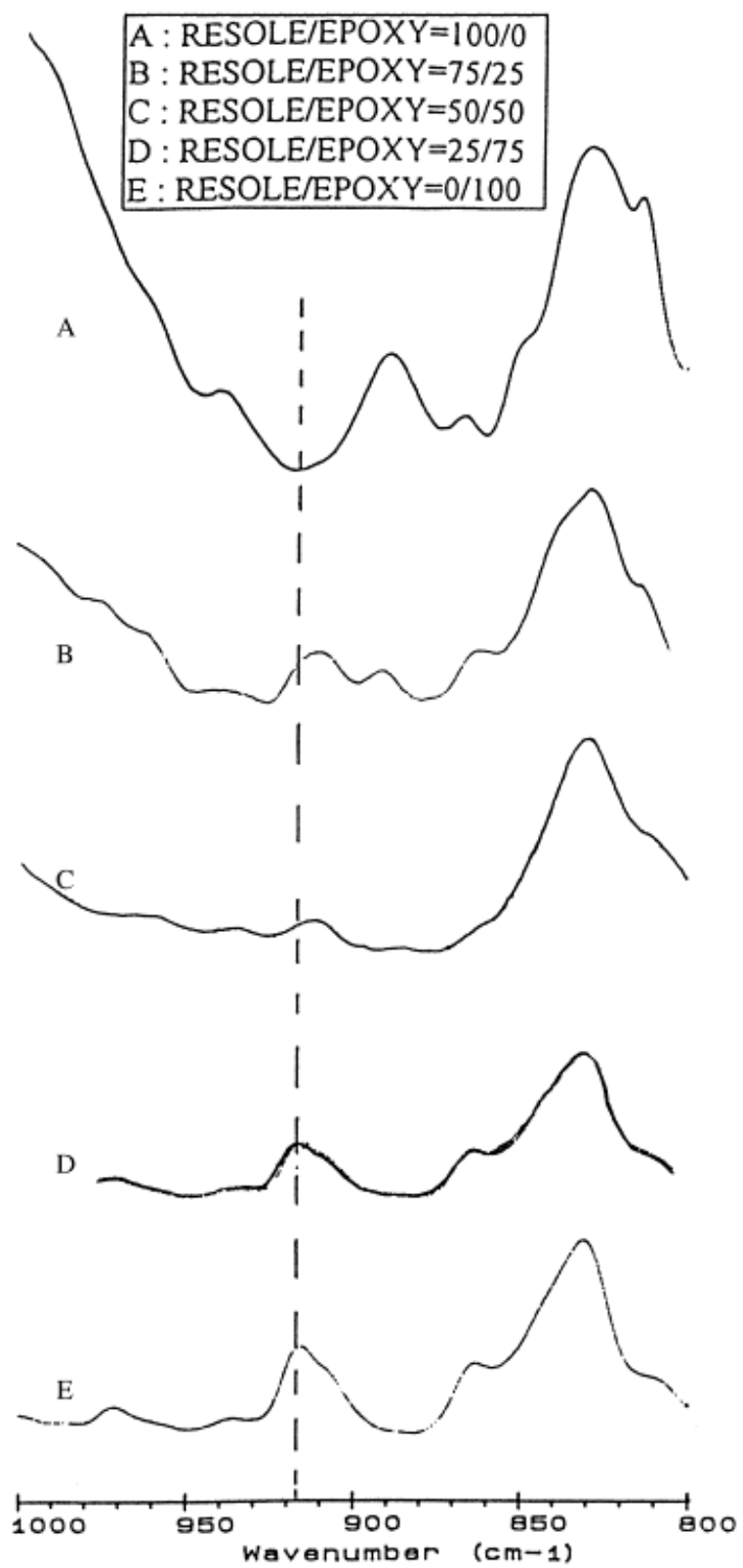

Figure 4 Epoxide band shifts in resole-epoxy blends.

resole-epoxy cocuring behaviors. Pure resole shows a curing exothermic peak at $160^{\circ} \mathrm{C}$ (Curve A), while epoxy has an exothermic peak at $164^{\circ} \mathrm{C}$ (Curve E). Each cocured composition of resole: epoxy $=75: 25$ and 50:50 (Curves B and C) indicates an additional peak at lower temperature, believed to be due to the cocuring reaction between the phenoxide in the resole and the epoxide in the epoxy.

That both compositions $\mathrm{B}$ and $\mathrm{C}$ indicate a main peak with a shoulder peak at a lower temperature might indicate partially miscibility of

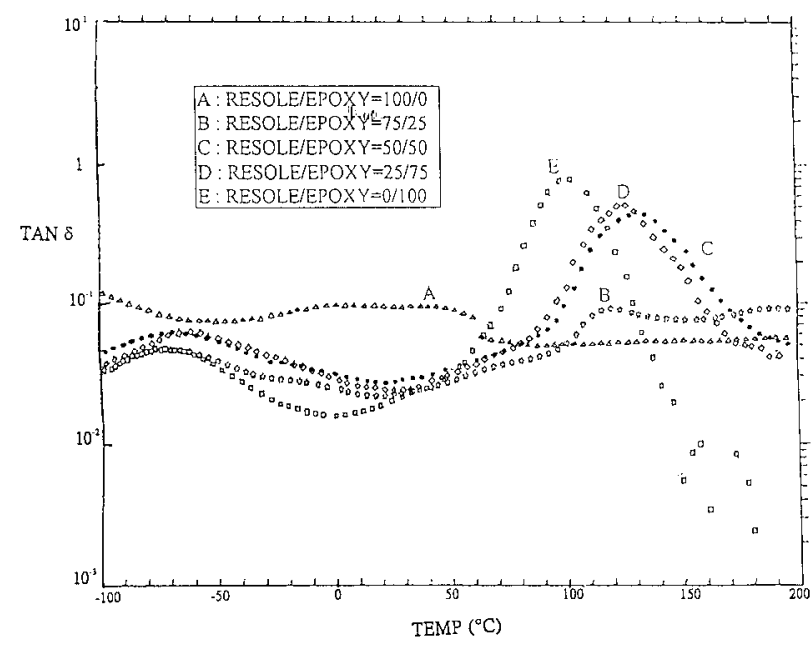

Figure 5 Damping peaks ( $\tan \delta$ ) for various resoleepoxy compositions.

the two components. However, only a broader single exothermic peak is observed for the composition of resole:epoxy $=25: 75$ (Curve D), presumably because the two components are miscible at this specific composition, and/or because the catalytic effect of the $\mathrm{OH}$ group (from $25 \%$ of resole) on the $75 \%$ epoxy cure shifts the main epoxide-NN cure peak to a lower temperature and thus covers the additional shoulder of the epoxide-phenoxide cure peak. The catalytic effect of $\mathrm{OH}$ on epoxide- $\mathrm{NH}$ cure is well known from the literature. ${ }^{7,8}$

The ${ }^{13} \mathrm{C}-\mathrm{NMR}$ spectra for cured resole and cured epoxy have been extensively studied in literature. ${ }^{9-13}$ The crosslinked epoxy cured by MDA

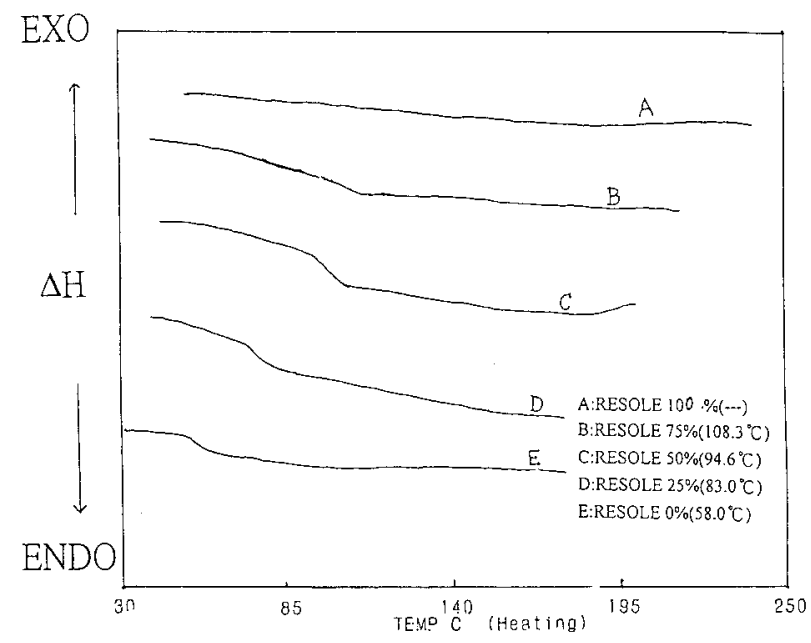

Figure 6 Glass-transition temperatures for various resole-epoxy compositions. 


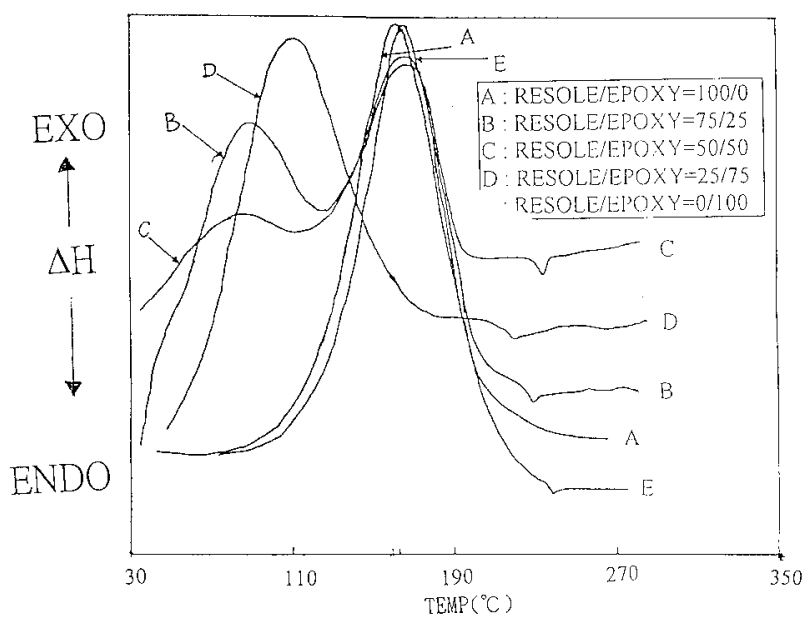

Figure 7 Dynamic DSC thermograms showing exothermic peaks for various resole-epoxy compositions during cocuring reactions.

shows a residual epoxide carbon at $50.7 \mathrm{ppm}$ (Fig. $8)$. The disappearance of this peak for the cocured 50:50 of resole:epoxy (Fig. 9) revealed the opening of the residual epoxide by a strong nucleophilic attack of the phenoxide group because phenoxide is a stronger nucleophile than the amine group transition.

The increases in viscosity during cocuring reactions at $100^{\circ} \mathrm{C}$ are given in Figure 10 . Both pure epoxy and resole cure at relatively slower rates and show pet-life, at $35 \mathrm{~min}$ for resole (Curve A) and at $33 \mathrm{~min}$ for epoxy (Curve E). Other compositions for resole:epoxy $=75: 25$, 50:50, and 25:75 (Curves B, C, and D) indicate faster cure rates, presumably because of the fast nucleophilic attack of phenoxide to epoxide

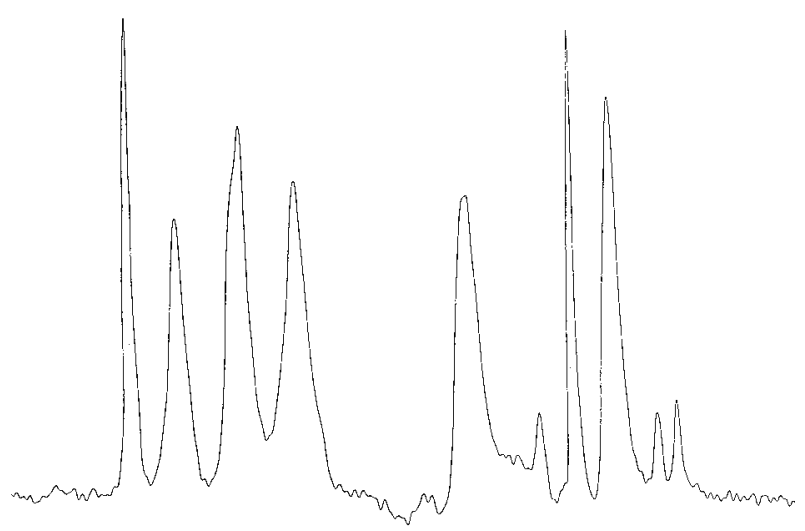

Figure $8{ }^{13} \mathrm{C}-\mathrm{NMR}$ spectrum for postcured epoxy.

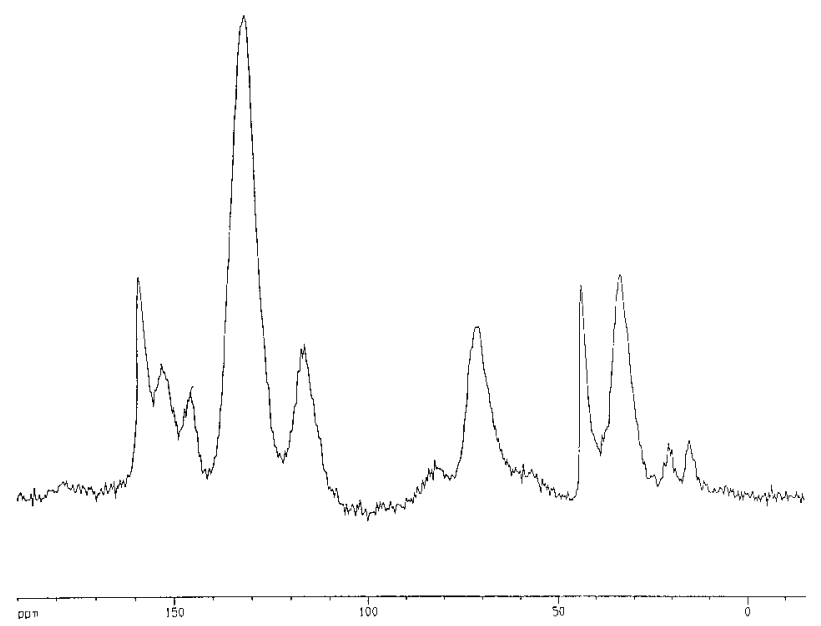

Figure $9{ }^{13} \mathrm{C}-\mathrm{NMR}$ spectrum for cocured 50:50 of resole:epoxy material

as well as a catalytic effect of the $\mathrm{OH}$ on the epoxy-MDA cure, as reported in the literature. ${ }^{1,14}$

A plot of $T_{g}$ versus percent resole content is given in Figure 11. It is notable that enhanced glass-transition temperatures for the cocured materials can be observed, which is different from IPN systems, which instead generally have decreased glass-transition temperatures. ${ }^{1,15}$ A plot of gel fractions versus percent resole content is shown in Figure 12. Again, enhanced gel fractions for the cocured samples (Curves B, C, and D) can be observed, while they have been known to decrease in IPN systems. ${ }^{1,15}$ These enhanced gel fractions would mean more crosslinking for each cocured sample and account for the enhanced glass transition.

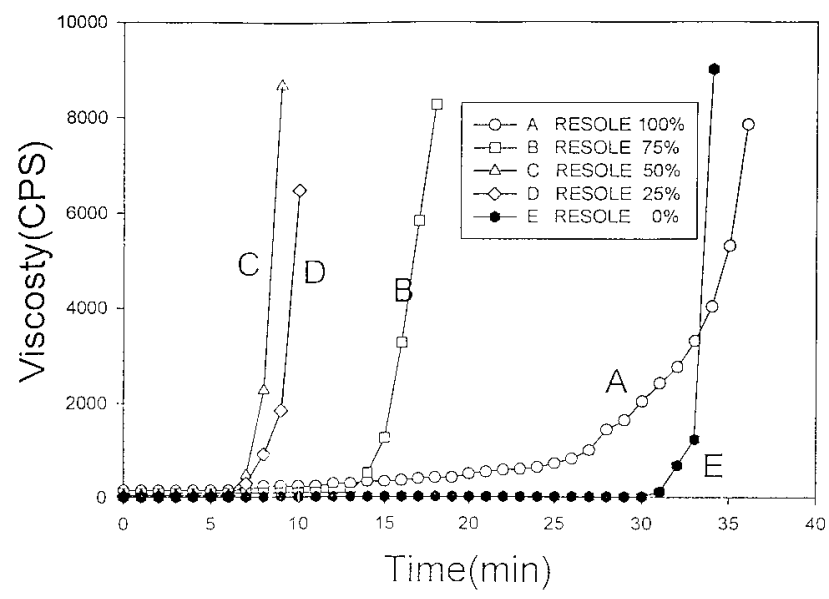

Figure 10 Viscosity increases for various resole-epoxy compositions during cocuring reactions. 


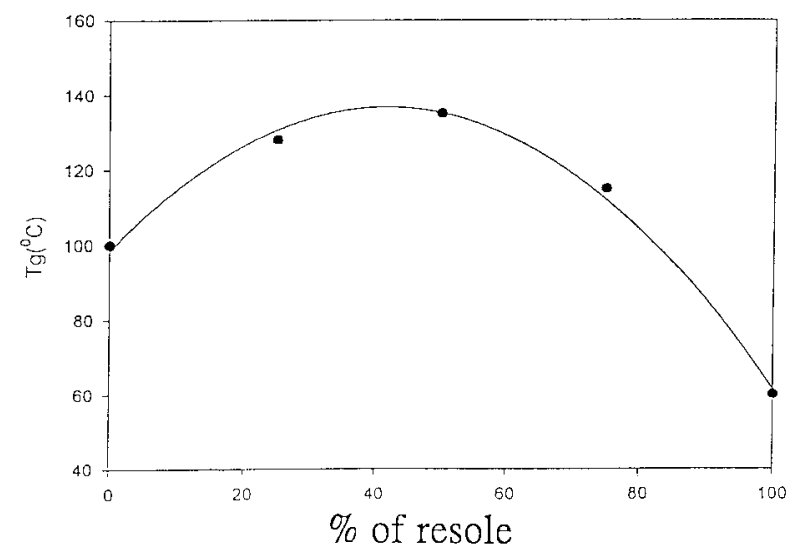

Figure 11 Plot of glass-transition temperature versus percent resole content.

Hourston proposed a method to calculate the average molecular weight $\left(M_{c}\right)$ between two linkages for a crosslinked polymer ${ }^{16}$ :

$$
T_{g}-T_{g, o}=3.9 \times 10^{4} / M_{c}
$$

where $T_{g}$ is the glass-transition temperature of a specific material and $T_{g o}$ is the glass-transition temperature of uncured epoxy $\left(-16.6^{\circ} \mathrm{C}\right)$. The calculated $M_{c}$ values are plotted in Figure 13. It can be noted that the $M_{c}$ value for a cocured sample (resole:epoxy $=75: 25,50: 50$, and 25:75) is generally smaller than that of epoxy. The $M_{c}$ value for resole is not shown in the plot because the highly rigid resole did not show a definite $T_{g}$, while higher $M_{c}$ values are generally found in full and semi-IPNs. ${ }^{1,15}$ The findings of higher $T_{g}$ values, lower gel fractions, and lower $M_{c}$ values strongly support the occur-

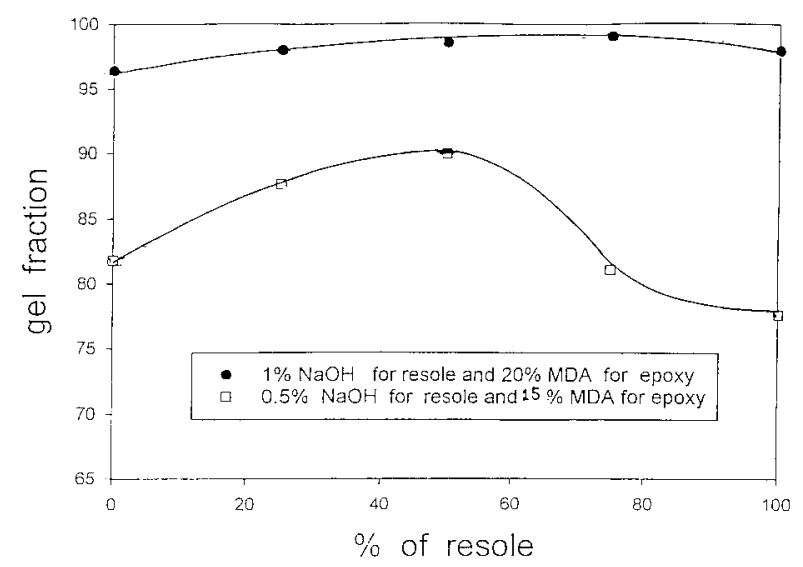

Figure 12 Plot of percent gel fractions versus percent resole content.

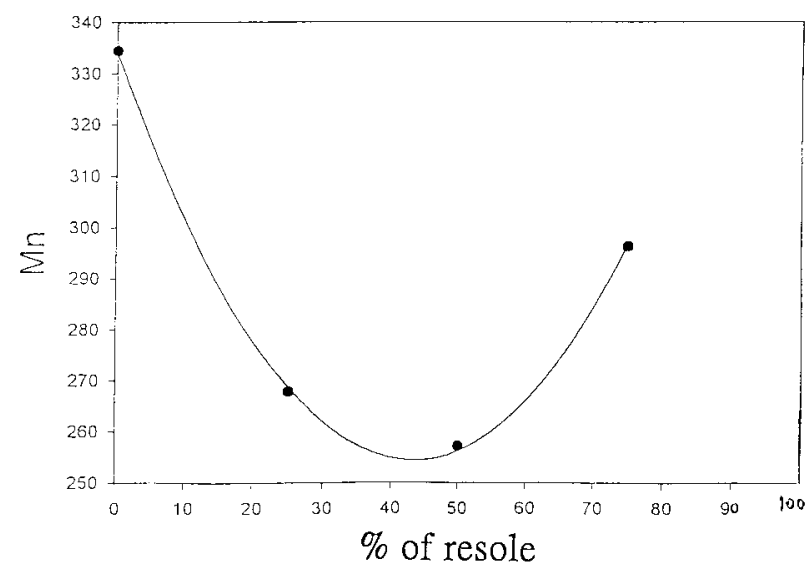

Figure 13 Plot of average molecular weight between linkages versus percent resole content.

rence of higher crosslinking in cocured polymer materials than in IPN materials because the chemical crosslinking between the two networks in cocured materials accounts for the experimental results. In IPN materials the physical chain entanglements in the two networks provide a sterically hindered environment and cause difficult and incomplete cure, leading to a lower gel fraction, a lower $T_{g}$, and higher $M_{c}$ values. ${ }^{1,2,15}$

\section{CONCLUSION}

In the compatible resole-epoxy cocured materials, enhanced gel fractions, increased glasstransition temperatures, and lower average molecular weight between linkages were found. These phenomena are different from those generally found in IPN systems, as reported in literature. Chemical crosslinking between the two networks in a cocured system would lead to higher crosslinking, while physical chain entanglements of the two networks in IPN materials would lead to lower crosslinking, thus accounting for these findings.

\section{REFERENCES}

1. Lin, M. S.; Lee, S. T. Polymer 1995, 36, 4567.

2. Lin, M. S.; Chang, R. J.; Yang, T.; Shih, Y. F. J Appl Polym Sci 1995, 55, 1607.

3. Steiner, P. T. J Appl Polym Sci 1975, 7, 19.

4. Fyfe, C. A. J Appl Polym Sci 1983, 28, 2611.

5. Small, P. A. J Appl Polym Chem 1953, 7, 71. 
6. Hoy, K. L. J Paint Technol 1970, 42, 76.

7. King, J. J.; Bell, J. P. Epoxy Resin Chemistry; Bauer, R. S., Ed.; American Chemical Society: Washington, DC; Vol. 114, p 223, 1979.

8. Ohashi, K.; Hasegawa, K.; Fukuda, A.; Uede, K. J Appl Polym Sci 1992, 44, 419.

9. Fyfe, C. A.; Mckinnon, M. S. Macromolecules 1983, $16,1216$.

10. Bryson, R. L. Macromolecules 1983, 16, 1669.
11. Maciel, G. E.; Chuang, I. S. Macromolecules 1984, 17, 108.

12. Roucsh, P. B. Polym Preprint 1983, 22, 274.

13. Cholli, A. Polym Preprint 1983, 24, 215.

14. Shech, L.; Wynstra, J.; Kurkyiy, P. E. Ind Eng Chem 1956, 48, 94.

15. Lin, M. S.; Liu, C. C.; Lee, C. T. J Appl Polym Sci 1999, 72, 585.

16. Hourston, D. J. J Appl Polym Sci 1983, 28, 3849. 